Felipe Oliver

DOI: $10.4312 /$ vh.24.1.217-229

Universidad de Guanajuato

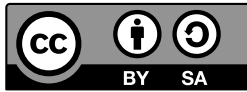

\title{
Alejandro Zambra. El cultivo del relato literario.
}

Palabras calve: Alejandro Zambra, bonsái, literatura chilena, metaficción, nouvelle.

La publicación en 2006 de Bonsái, situó de inmediato al chileno Alejandro Zambra como uno de los escritores jóvenes más representativos de la literatura hispanoamericana contemporánea. En efecto, a sólo unos meses de su publicación, Bonsái recibió en el 2007 los dos premios literarios más importantes que concede la nación cordillerana; el Premio de la Crítica de Chile, y el Premio del Consejo Nacional del Libro, además de quedar como finalista del Premio Altazor el mismo año, y del Best Translated Book en el 2008. Como dato adicional, la novela fue publicada por Anagrama, lo que sin duda constituye ya un logro significativo tratándose de una primera novela escrita por un autor de treinta años. Ahora, si algo distingue a esta obra es la simplicidad absoluta en lo relativo al argumento en oposición a una enorme riqueza plástica y un nutrido diálogo con referencias intertextuales. Dicho con otras palabras, la novela renuncia de antemano a la elaboración de una trama compleja capaz de generar intriga, pero seduce al lector gracias a una sugerente simbolización que dota a la narración de una profundidad que contrasta con la simplicidad de lo narrado. En ese sentido el título adquiere especial relevancia pues sugiere un paralelismo entre la complejidad técnica del relato literario con la ancestral práctica oriental del cultivo de árboles y plantas. Este trabajo pretende entonces una lectura de la novela de Zambra a la luz del bonsái, símbolo sugestivo que dota al relato de una gran complejidad estilística que contrasta con su simplicidad argumental.

Al final ella muere y él se queda solo, aunque en realidad se había quedado solo varios años antes de la muerte de ella, de Emilia. Pongamos que ella se llama o se llamaba Emilia y que 
él se llama, se llamaba y se sigue llamando Julio. Julio y Emilia. Al final Emilia muere y Julio no muere. El resto es literatura: (Zambra, 2006: 13).

Con estas palabras inicia la novela. El párrafo inaugural, está claro, resume toda la información: la heroína, Emilia o cualquier otro apelativo que el lector decida otorgarle, muere y Julio se queda solo. Implícitamente el lector recibe además otro dato no menos significativo y desalentador: se trata de una historia de amor irremediablemente frustrado. Esta primera entrada enmarca el texto dentro de ciertas coordenadas genéricas, ya muy desgatadas por lo demás, y de paso adelanta el final, desterrando cualquier posibilidad de misterio. Al parecer, Zambra no estaría en desacuerdo con Jorge Luis Borges cuando el argentino afirmó que escribir novelas es ocioso e inútil pues basta con resumir el argumento en un par de oraciones. Sin embargo, algo hay de perturbador en la última oración: «El resto es literatura:» (Zambra, 2006: 13). Una pequeña aclaración, la oración no termina con un punto final sino con los dos puntos. A continuación hay un espacio en blanco tan evidente y deliberado que es imposible no advertirlo. El texto recomienza entonces después de dos marcas textuales claras e intencionadas, los dos puntos y el espacio en blanco. Considerando estos datos, el párrafo inaugural cobra un nuevo sentido como una advertencia que rompe con el pacto mimético. Lo que leerá el lector a continuación es ficción, una trillada historia de amor en donde los «hechos» carecen de importancia, no en vano ya ha sido dado a conocer el desenlace. Por consiguiente, el foco de interés se centrará en lo sucesivo en el artificio, no en lo que se cuenta sino en el cómo se cuenta.

El bonsái como un símbolo que soporta la narración comienza a cobrar sentido. La ancestral técnica oriental consiste en cultivar árboles y reducir drásticamente su tamaño mediante distintas técnicas. Si acaso vale la expresión, se trata de una arboricultura de lo mínimo. Principio que Zambra pareciera trasladar al texto literario al construir una novela cuya extensión total no alcanza las cien páginas, en la que los personajes apenas si han sido delineados, y en donde el argumento es de una simpleza tal que es resumible en un sólo párrafo. En palabras de Álvaro Enrigue,

Estamos con este libro, entonces, ante una doble negación: la novela como género épico ya no tiene el menor interés y la muerte no es narrable. O desde otro punto de vista: si los valores ya cambiaron y ninguna muerte es prestigiosa - por amor, por servicio, por valentía- la novela como género es sólo 
personal; ya no cuenta el fragor de las vidas ejemplares, sino la tímida medianía de los que enfrentan sin gestos vistosos el momento definitivo de sus vidas; un paso más allá -paso al abismo- de la desmitificación que proponía Ortega y Gasset como sentido novelesco. (2007: 77)

¿Qué queda entonces para la novela? Una vez más, el artificio, la posibilidad de construir un bonsái cuya nimia extensión, personajes sin profundidad psicológica, argumento trillado y simplicidad estructural, sea contrarrestada por una riqueza intertextual e ingeniosos juegos metaficcionales que posibiliten por un lado el diálogo con múltiples obras literarias emanadas de distintas tradiciones, y por el otro que reflexione sobre la futilidad misma del proceso creativo. Y es en este punto que la arboricultura oriental como un soporte del texto literario redondea su utilidad y efectividad. El bonsái es por principio una práctica contranatural. El simple hecho de injertar un árbol en un espacio regulado para posteriormente guiar su crecimiento, cuidando en todo momento no exceder ciertas dimensiones risibles, supone suplantar a la naturaleza por la intervención artesanal del hombre. La poda posterior destinada a simular o evocar una determina escena confirma el simulacro, la intervención del artista en la construcción de un artificio. No nos confundamos: el árbol es real, pero las condiciones en las que subsiste no, por lo que se trata de un objeto artificial en el sentido en que ha sido adulterado. Y son justamente estos procedimientos de injerto, poda y simulacro en los que Zambra encuentra una traducción del oficio literario. Ahondemos en esta dirección.

Cerca del final del Bonsái, el reconocido escritor Gazmuri contrata a Julio para que transcriba en ordenador el borrador de su última novela, una historia personal sobre un hombre que accidentalmente se «entera que una polola de juventud ha muerto» (Zambra, 2006: 67). Un dato importante, Gazmuri se obstina en escribir con puño y letra sobre el papel, siendo esa la razón por la que necesita de los servicios de Julio. Pero este último en lugar de transcribir las palabras de Gazmuri, comienza a escribir su propia novela simulando que transcribe la obra de Gazmuri. Y la «novela» de Julio se titula precisamente Bonsái, a la que el propio Julio define con las siguientes palabras:

En Bonsái prácticamente no pasa nada, el argumento da para un cuento de dos páginas, un cuento quizá muy no muy bueno [...] ¿Los personajes? [...] Él y Ella, Huacho y Pochocha, no tienen nombres y a lo mejor tampoco tienen rostros. El protagonista 
es un rey o un mendigo, da lo mismo. Un rey o un mendigo que deja ir a la única mujer que realmente ha amado. (Zambra, 2006: 76)

Dentro de la novela Bonsái escrita por Alejandro Zambra, un personaje ficticio escribe un texto titulado Bonsái que remeda a la obra de Zambra. La similitud es tan deliberada que incluso en las páginas finales de la novela Julio pinta un bonsái sobre una hoja de papel, y el dibujo coincide con la portada del libro:

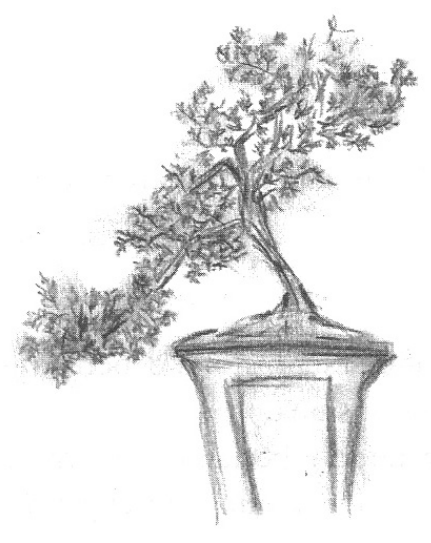

1. Bonsái pintado por Julio dentro de la ficción

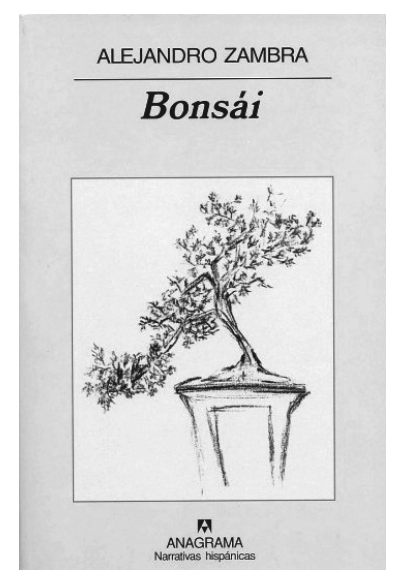

2. Portada de la novela Bonsái de Alejandro Zambra 
Se trata, desde luego, de un recurso frecuente en la metaficción que Lucien Dällenbach (1991) define como «puesta en abismo» (mise en abyme) y que consiste justamente en duplicar la ficción dentro de la ficción misma, como en un juego de espejos en donde el reflejo de un objeto se prolonga infinitamente en otro reflejo. Recurso del que Zambra no sólo es consciente, sino que lo remarca explícitamente al señalar que «es un árbol es precipicio». Abismo y precipicio, vocablos tan cercanos que pueden ser utilizados como sinónimos. «Todo enclave que guarde relación de similitud con la obra que lo contiene» (Dällenbach, 1991: 61) se convierte entonces en una puesta en abismo que dota de niveles de profundidad ficcional a la ficción misma, como el árbol/relato dibujado por Julio. ¿Zambra escribe a Julio o Julio escribe a Zambra?

El problema se complica si consideramos que Julio reescribe lo que supone que Gazmuri pudo haber escrito, y tanto el resumen esbozado por el propio Gazmuri de su obra original como la suposición de Julio responden, justamente, a las características de la novela escrita por Zambra. Por último, y como se verá más adelante, Bonsái es de hecho una reescritura de un cuento de Macedonio Fernández titulado Tantalia. En cualquier caso, la ficción toma conciencia sobre sí misma para definir y explicar su propia poética constitutiva. Más aún, mediante el juego de espejos/injertos confirma su artificialidad como un simulacro de una obra previa imputada a otro, ¿Gazmurie, ¿Macedonio Fernández? De hecho, Zambra prolonga el entramado artificial en su siguiente obra, La vida privada de los árboles publicada en 2007 . La segunda novela de Zambra pone en escena a un personaje en una situación de absoluta cotidianidad. Julián es un profesor universitario y escritor en ciernes que a lo largo de una noche mata las horas a la espera de que su pareja, Verónica, vuelva a casa después de su clase de dibujo. Mientras Julián espera, el narrador nos informa que el protagonista:

Acaba de terminar un libro muy breve, que sin embargo le tomó varios años escribir. En un principio se dedicó a acumular materiales: llegó a juntar casi trescientas páginas, pero luego fue descartando pasajes, como si en lugar de sumar historias quisiera resaltarlas o borrarlas. El resultado es pobre: una escuálida resma de cuarenta y siete hojas que él se empeña en considerar una novela. (Zambra, 2007: 27, 28)

[...] 
Ahora lee, está leyendo: se esfuerza en fingir que no conoce la historia [...] convenciéndose de que tiene ante sus ojos el texto de otro. (2007: 28)

$[\ldots]$

La imagen primera es la de un hombre joven dedicado a cuidar un bonsái. Si alguien le pidiera resumir el libro, probablemente respondería que se trata de un hombre joven que se dedica a cuidar un bonsái. (2007: 28, 29)

Se hace evidente entonces que el personaje de La vida privada de los árboles es de algún modo el autor de Bonsái. Julio y Julián, los nombres mismos generan más incógnitas que certezas, e incluso Julián al releer su manuscrito hace lo posible por convencerse que se trata de la escritura de otro. El proyecto literario de Zambra acaso puede ser definido como un complejo engranaje en donde:

Por una parte, su narrativa se centra en entrelazar tanto los personajes como los libros que el mismo escribe, escribió o está a punto de escribir, y por otra, la de quitar el peso al lenguaje de las redundancia y solo centrarse en describir aspectos mínimos y simples de las relaciones humanas. (Astudillo, 2008: 76)

Bonsái no termina cuando el lector llega a la ùltima página; el juego de citas y pastiches, los juegos metaficcionales y los personajes mínimamente trazados continúan en La vida privada de los árboles, obligando a re-leer la primera novela a la luz de lo planteado en la segunda. El árbol/relato continúa cayendo por el precipicio ficcional hasta confundir los niveles mismos de la diégesis, pues no está claro cuál es el marcorelato que contiene a los demás.

Pero volviendo a Bonsái, el narrador explícitamente compara el proceso creativo de la escritura con el cultivo y cuidado del bonsái. «Cuidar un bonsái es como escribir, piensa Julio. Escribir es como cuidar un bonsái, piensa Julio». (Zambra, 2006: 87) Esta reflexión, tomada directamente de la novela, confirma un símil que más que ingenioso parece trillado. Pero Zambra no pretende develar el hilo negro del proceso creativo: al contrario, lo expone de una manera tan abierta y obvia que el objetivo final pareciera apuntar a construir en unas cuantas páginas una gran farsa tanto del proceso de la escritura como el de la lectura. De hecho, el romance entre Julio y Emilia inicia con una farsa literaria: ambos personajes, acaso para parecer más interesantes frente al otro, aseguran haber leído a Proust. Emilia incluso llega a afirmar «me propuse leer 
los siete tomos y la verdad es que ésos fueron los meses más importantes de mi vida como lectora» (2006: 24). La joven añade, disculpándose, que la lectura le tomó cinco meses pues andaba atareada con las materias en la universidad. La mentira funciona, pues a partir de esa noche la relación entre ambos cobra seriedad y profundidad. En lo sucesivo, Zambra destinará varias páginas de su cortísima novela a referir los libros que Julio y Emilia leen antes del sexo: Rubén Darío, Marcel Schowb, Yukio Mishima, Georges Perec, Juan Carlos Onetti, Raymond Carver, la Antología de la Literatura Fantástica de Adolfo Bioy Casares, Jorge Luis Borges y Victoria Ocampo y así un largo etcétera. Como el bonsái que ha sido trasplantado de su medio e injertado en un espacio otro, la novela transcurre entonces como un conjunto de pastiches, alusiones explícitas o veladas a diversas fuentes, y fragmentos de distintas obras literarias injertadas en el cuerpo de la novela.

Ahora, dos serán los textos que cobrarán especial relevancia en la relación de los jóvenes universitarios; Tantalia de Macedonio Fernández y, precisamente, en Busca del tiempo perdido de Marcel Proust. El primer relato versa sobre una pareja que decide criar una plantita como símbolo de su amor. A la larga, la planta les generará una enorme angustia pues si llega a morir el amor entre ambos igualmente perecerá. Desesperados deciden entonces esconder la plantita dentro de una multitud de plantas similares, pero el quiebre se produce cuando cobran conciencia que jamás podrán recuperarla. La lectura de Macedonio Fernández afecta a los personajes, en especial a Emilia, y a partir de ese momento se produce un distanciamiento.

El cuento de Macedonio Fernández, está claro, es un buen resumen de la novela de Zambra; ya ha sido mencionado que ésta trata sobre un amor frustrado. Agreguemos ahora que las páginas finales Julio decide cultivar un bonsái como un homenaje a Emilia, la única mujer que ha amado. Alejandro Zambra deja claro entonces que su novela es una reelaboración de un texto previo de Macedonio Fernández, amén de los múltiples espejos al interior de la misma ficción con los cuales busca confundir al lector, como Julio y Gazmuri. Por consiguiente, la novela deja poco margen de especulación sobre los motivos ocultos que pudieron haber inspirado a su autor (es) y abiertamente muestra los trasplantes e injertos que germinaron en su propio relato. En palabras de Macarena Silva,

Bonsái se vuelve escritura de la escritura, la novela que el personaje de ficción escribe pero que llega a las manos de nosotros sus lectores desarticulando los límites convencionales entre lo real y lo ficticio. En ella la metaficción y la apropiación 
de la literatura que realizan los personajes son estrategias que parodian ciertos tópicos literarios y que evidencian el fracaso de la idea de que la literatura completa y enriquece la existencia de quienes la leen (2007: 10).

Bajo este punto de vista, queda en evidencia entonces que la literatura es representada por Zambra como una gran farsa que recorre toda la novela. El acto de leer es practicado más como una pose que como una experiencia estética o intelectual. El mismo Zambra describe a Julio y Emilia con las siguientes palabras:

Esta es la historia de dos estudiantes aficionados a la verdad, a fumar cigarros eternos, y a encerrarse en la violenta complacencia de los que se creen mejores, más puros que el resto, que ese grupo inmenso y despreciable que se llama el resto. (Zambra, 2006: 25-26)

Hay un dejo claro de sarcasmo en el tono empelado por Zambra que establece una distancia al mirar a sus personajes, casi presentándolos con ternura paternal. Así, cuando Julio se «avienta» una más de sus «lúcidas» revelaciones comparando la escritura con el bonsái, su capital simbólico ha quedado tan desgastado que el lector sonríe en lugar de deslumbrarse. Después de todo Julio, al igual que en su momento Emilia, creyó que la lectura, los cigarros metafísicos y la búsqueda de la verdad lo hacía mejor que el resto sin sospechar siquiera que en su convicción remedaba el comportamiento trillado y estereotípico del estudiante de letras promedio en los primeros semestres de la carrera. La superioridad intelectual de Julio es una farsa, al igual que sus lecturas de Proust.

El quiebre definitivo se produce cuando la pareja decide leer a Proust, fingiendo a cada instante que se trata de una relectura. La obra del francés es, acaso, la mayor burla dentro de la obra de Zambra. En efecto, el mismo Proust que levantó todo un edificio narrativo a partir del complejo juego de simulaciones e hipocresías sociales, se ha convertido en un autor al que nadie lee pero todos citan para simular erudición y superioridad moral e intelectual. De ahí que cuando el simulacro comienza a adquirir visos de realidad porque Julio y Emilia efectivamente están leyendo su obra, la relación termina. El amor de Julio es muy real, pero el pacto en el que se sostiene su relación es falso, como el bonsái al que acaso podemos comparar con un simulacro de árbol.

Por otro lado, el bonsái como un símbolo que sostiene la obra de Zambra reside fundamentalmente en el protagonista: 
Julio escabullía las relaciones serias, se escondía no de las mujeres sino de la seriedad, ya que sabía que la seriedad era tanto o más peligrosa que las mujeres. Julio sabía que estaba condenado a la seriedad, e intentaba, tercamente, torcer su destino serio, pasar el rato en la estoica espera de aquel espantoso e inevitable día en que la seriedad llegaría a instalarse para siempre en su vida. (Zambra, 2006: 16)

Y efectivamente, hasta el momento en que termina la cortísima novela de Zambra, Julio sigue evadiendo la seriedad. Nos enfrentamos al eterno adolescente, acaso víctima de lo que la piscología popular explica desde el concepto del síndrome de Peter Pan. Es un personaje atrapado, reducido profesional y emocionalmente, como el bonsái aprisionado al que no se le permite seguir creciendo dentro de su maceta. «Los Árboles son elementos arraigados en un solo lugar. Simbolizan el contexto familiar del ámbito casero, las cosas que no cambian, que siempre están ahí». (Willem, 2014: 55-56) Terminada la relación, Emilia tiene nuevas parejas, emigra a Madrid y finalmente, después de caer en un círculo de degradación que incluye drogas y promiscuidad, se suicida. Julio se queda en Santiago de Chile y cuando sus padres se rehúsan a seguir manteniéndolo comienza a vender sus libros o a conseguir trabajitos esporádicos para subsistir. Julio permanece estancado en el pasado, incapaz de enfrentar y trascender aquello que él mismo denomina como la «seriedad». Felipe Ríos Baeza (2013) atribuye el carácter de Julio a las lecturas japonesas de Zambra; de acuerdo con el crítico, la lectura de autores como Köbö Abe, Kenzaburo Oé o Yukio Mishima, acaso explican el carácter pasivo y netamente contemplativo de Julio, pues la narrativa de Zambra es «una literatura "puertas adentro", donde los personajes puedan recrearse en esas sensibles "ceremonias de interior"» (Ríos, 2013: 84). En las narrativas japonesas que Zambra sin duda conoce, actos al parecer nimios como fumar un cigarrillo, pintar un cuadro o leer un libro suponen acciones en sí mismas profundas y complejas que al ser narradas adquieren un valor interior casi trascendental. Una vez más, el bonsái se convierte en un símbolo vital que remite a todo un sistema narrativo que conecta a literariamente Zambra con el lejano oriente.

Ahora, siendo Zambra un escritor chileno nacido en la década del setenta, es tentador leer el estancamiento de Julio desde la historia reciente de su país. Aunque Bonsái, ha sido mencionado hasta el cansancio, es una metaficción que por momentos rinde homenaje a ciertos textos pero ante todo se burla del proceso mismo de la lectura y la escritura, se inserta irremediablemente dentro 
de una larga lista de obras y autores contemporáneos que reflexionan sobre los grandes hitos del pasado: el efímero gobierno socialista de Salvador Allende, la larga dictadura militar encabezada por Augusto Pinochet, y la reforma económica neoliberal implantada en la década del noventa con el advenimiento de la democracia. Bajo este punto de vista, Julio muy bien podría representar al perdedor prototípico de la transición. Entiendo por esto un joven que permanece atrapado por el peso de la memoria histórica, incapaz de superar el fin de la utopía y la caída de los relatos, incapaz de adaptarse a los modos de vida y construcción de la subjetividad que trajo consigo el Chile neoliberal. De acuerdo, una vez más, con Ríos Baeza:

lo que se narra es una historia que no parece historia, ya que no parece fluir: la del Chile gris del periodo post-dictatorial. Para referir estéticamente un tiempo estancado, donde la historia de los hijos aparece sepultada debajo de la historia de los padres (esos padres que enfrentaron el golpe militar de Pinochet y sus heridas sociales), Zambra encuentra en la impostura de la traducción de las novelas japonesas el modelo ideal para sacar adelante su proyecto literario. (2013: 81, 82)

Los trabajos posteriores de Alejandro Zambra, en efecto, exploran con mucho mayor profundidad la memoria histórica chilena. Por decirlo de algún modo, de un libro a otro Zambra se ha ido politizando. En La vida privada de los árboles (2007) la dictadura no es mencionada explícitamente en ningún momento, pero claramente es el elemento que sostiene toda la trama narrativa. $Y$ en su novela del 2011, Formas de volver a casa, la reconstrucción de la memoria histórica es abordada y discutida abiertamente. Así, mirando en retrospectiva la obra de Zambra, es tentador buscar en Bonsái los primeros indicios de una lectura política. El estancamiento de Julio simbolizado por el arbolito al que le han negado la posibilidad de crecer es tal vez una metáfora para representar a toda una generación cortada desde la raíz e injertada en un espacio otro por el gobierno dictatorial.

Esta lectura, insisto, es tentadora, pero lo fundamental de Bonsái reside en la reflexión paródica del proceso de la lectura y la escritura. La novela pone en escena el juego de préstamos e influencias que interviene en la génesis de un texto, el que sea. La novela como género literario revela entonces su artificialidad, pues en el fondo toda novela es una re-elaboración de un discurso previo. La lectura, por su parte, es cuestionada al presentarse como un simple ejercicio que concede cierto status, que confiere al sujeto un capital simbólico, pero que 
no necesariamente desata o genera una reflexión intelectual o una experiencia estética. El resultado final es una obra inquietante y polisémica, abierta a varias lecturas a pesar de su simplicidad y su cortísima extensión.

\section{Bibliografía}

Astudillo, C. (2008): «La novela de las novelas: Mise en Abyme y metanovela en dos novelas de Alejandro Zambra: Bonsái y La vida privada de los árboles». En: Logos: Revista de Lingüistica, Filosofía y Literatura, 18 (1), 75-84.

Bieke, W. (2014): «Narrar la frágil armadura del presente. La paradójica cotidianidad en las novelas de Alejandro Zambra y Diego Zuñiga». En: Interférences littéraires/Literaire interferenties, 13, 53-67.

Dällenbach, L. (1991): El relato especular. Madrid: Editorial Visor.

Enrigue, Á. (2007): «La vida privada de los árboles y Bonsái de Alejandro Zambra». En: Letras Libres, 108, 75-77.

Ríos Baeza, F. (2013): «Orientalismo. La estética de la novela japonesa en la narrativa de Alejandro Zambra». En: Revista Isla Flotante. Academia de Humanismo Cristiano. 5: 77-86.

Silva, M. (2007): «La conciencia de reírse de sí: metaficción y parodia en Bonsái de Alejandro Zambra». En: Taller de Letras, 41, 9-20.

Zambra, A. (2006): Bonsái. Barcelona: Anagrama.

Zambra, A. (2007): La vida privada de los árboles. Barcelona: Anagrama. 
Felipe Oliver

University of Guanajuato

\section{Alejandro Zambra. The Art of Planting a Novel.}

Keywords: Alejandro Zambra, Bonsái, Chilean literature, metafiction, nouvelle.

The appearance of Bonsai in 2006, immediately placed Alejandro Zambra as one of the most representative writers of contemporary young Latin American literature. This novel of an absolute simplicity proposes however a very rich and complex framework of intertextuality. The title in fact is particularly relevant as far as it suggests a parallel between the complex technical of writing with the ancient Oriental practice of growing miniature trees. This paper seeks a reading of the novel of Zambra through its Bonsai symbolism. 
Felipe Oliver

Univerza v Guanajuatu

\section{Alejandro Zambra. Gojenje literarne pripovedi}

Ključne besede: Alejandro Zambra, Bonsái, čilska književnost, metafikcija, nouvelle

Ko je čilski pisatelj Alejandro Zambra leta 2006 izdal Bonsái, je takoj obveljal za enega najprepoznavnejših mladih avtorjev sodobne hispanoameriške književnosti. Roman je vsebinsko popolnoma preprost, vendar ga odlikujeta neverjetna plastičnost in bogata intertekstualnost. $V$ tem pogledu je naslov še posebej zgovoren, saj kaže na vzporednice med tehnično kompleksnostjo literarne pripovedi ter starodavno vzhodnjaško tehniko gojenja dreves in rastlin. Pričujoči prispevek je torej branje Zambrovega romana skozi prizmo bonsaja: ta sugestivni simbol romanu vdihuje slogovno kompleksnost, ki je kontrast njegovi vsebinski preprostosti. 